\title{
DESENVOLVIMENTO DE BIOCONSERVANTE NATURAL PARA APLICAÇÃO EM ALIMENTOS
}

\author{
K. Q. BUCHOLDZ ${ }^{1}$ \\ ${ }^{1}$ CENTRO UNIVERSITÁRIO TUPY (UNISOCIESC), Departamento de Engenharia Química \\ E-mail para contato: karine,bucholdz@ sociesc.org.br
}

\begin{abstract}
RESUMO - Os ingredientes vegetais e cereais entram em contato direto com desafios ambientais com possíveis contaminações microbiológicas durante o plantio, colheita, produção, armazenagem e no próprio transporte. Com isso, existe a necessidade de desenvolver alternativas de conservação para que seja possível disponibilizar produtos mais seguros sob o ponto de vista microbiológico. O presente estudo teve como objetivo desenvolver um bioconservante capaz de inibir o crescimento de Salmomella spp. em Farelo de Soja destinado à alimentação animal. A ideia em questão é a produção de bacteriocinas, ou seja, peptídeos ou proteínas biologicamente ativas que possuem ação bactericida e/ou bacteriostática. Foram utilizadas cepas mistas de Lactobacillus na fermentação do melaço de soja. Verificou-se que a quantidade mínima necessária para inibição da $S$. choleraesuis foi de $0,2 \%$ e para inibição da $S$. mbandaka foi de $0,4 \%$. O bioconservante desenvolvido apresentou grande potencial para utilização em alimentos.
\end{abstract}

\section{INTRODUÇÃO}

A contaminação dos alimentos é um grande problema devido às altas taxas de morbidade. Desta forma, existe a necessidade de desenvolver alternativas naturais para a conservação de alimentos. Hoje em dia, a presença de Salmonella spp. é uma das mais importantes barreiras sanitárias em exportações, pois implica na rejeição do produto pelo cliente e possível rescisão de contratos.

De acordo com Jack et al. (1995) praticamente todas as bactérias têm a capacidade para a produção de substâncias durante o seu crescimento "in vitro" que seja inibitório para si ou para outras bactérias. Estas substâncias exercem efeito bactericida ou bacteriostático.

Industrialmente, as bacteriocinas e outros antimicrobianos são naturalmente muito atraentes devido ao apelo de segurança. As bactérias láticas interferem na multiplicação de bactérias patogênicas através de vários mecanismos. A produção de bacteriocinas tem sido evidenciada em bactérias láticas associadas com alimentos, envolvendo Lactococcus spp., Lactobacillus spp. e Pediococcus spp. (De Martinis et al. 2002, Rosa et al. 2002). 
O conhecimento e o uso desses fatores combinados em um alimento formam a teoria de obstáculos, que permite o controle do prazo de validade, a estabilidade microbiológica, bem como a prevenção da multiplicação e/ou produção de toxinas por microrganismos patogênicos eventualmente presentes (De Martinis et al., 2002).

No presente estudo foi realizada a incorporação de melaço de soja fermentado por bactérias láticas pré selecionadas e a sua aplicação nas formas líquida e em pó para preservação do Farelo de Soja para avaliação do efeito inibidor contra a Salmonella spp.

\subsection{Ingredientes para Alimentação Animal e Contaminação}

Ingredientes vegetais são altamente suscetíveis à contaminação por microrganismos durante o plantio, colheita, produção, armazenamento e transporte. Hoje em dia, é inegável a necessidade de monitoramento da presença de microrganismos em ingredientes para rações. Proteínas obtidas a partir de indústrias de óleos vegetais em são mais suscetíveis à contaminação por Salmonella spp. (Morita et al, 2003; European Food Safety Authority, 2006).

\subsection{Salmonella spp.}

Salmonella spp. é um microrganismo anaeróbico facultativo, gram-negativo que pertence à família Enterobacteriaceae. A sua temperatura óptima de crescimento é $37^{\circ} \mathrm{C}$, pH entre 4,5 e 9,5 , e atividade de água acima de 0,93. Produz ácido e gás a partir de glucose e outros carboidratos e não utilizam lactose e sacarose. É oxidase negativa e catalase positiva, capaz de usar citrato como única fonte de carbono para seu desenvolvimento. $\mathrm{Na}$ maioria dos casos, produz $\mathrm{H}_{2} \mathrm{~S}$, descarboxila lisina e ornitina e não hidrolisa a ureia (D'Aoust, 2001). É um microrganismo que pode causar doenças em seres humanos e animais (Pelczar et al, 1981; Nascimento et al, 2000) e é um dos mais estudados (Nascimento et al, 2000). Causam graves problemas para a agricultura industrial e para a saúde pública (Andrade et al, 1995; Tessari, 2003).

\subsection{Bacteriocinas}

Em meados de 1925, André Gratia apresentou um estudo sobre o potencial de inibição do crescimento de Escherichia coli em outras cepas da mesma espécie (Jack et al, 1995). Após a revelação de que a obtenção destes compostos não era limitada ao grupo coliforme, sugeriu-se o termo "bacteriocinas" para proteínas antimicrobianas produzidas por microrganismos gram-negativas e gram-positivas (Nascimento et al., 2008). Se utilizado em alimentos, as bacteriocinas podem ajudar a reduzir o uso de produtos químicos conservantes e/ou a intensidade de calor e outros métodos físicos, satisfazendo as necessidades dos clientes. Nos últimos anos, um intenso esforço que você tem-se feito para desenvolver aplicações de bacteriocinas em alimentos (Todorov, 2009). 


\section{MATERIAIS E MÉTODOS}

\subsection{Cepas}

As cepas utilizadas no presente estudo foram adquiridas da Fundação Andre Tosello, com exceção da cepa de Salmonella mbankaka que foi isolada do ambiente de uma indústria de Farelo de Soja. A Tabela 1 demonstra a temperatura de crescimento de cada cepa utilizada.

Tabela 1 - Cepas e temperaturas utilizadas neste trabalho

\begin{tabular}{lc}
\hline \multicolumn{1}{c}{ Cepas de Micorganismos } & T $\left({ }^{\circ} \mathbf{C}\right)$ \\
\hline Lactobacillus salivarius & 37 \\
Lactobacillus reuteri & 37 \\
Lactobacillus plantarum & 30 \\
Lactobacillus agilis & 30 \\
Lactobacillus plantarum (8014) & 37 \\
Lactobacillus acidophilus & 37 \\
Lactobacillus fermentum & 37 \\
Salmonella enterica subsp. enterica serovar & 37 \\
choleraesuis & \\
Salmonella enterica subsp. enterica serovar & 37 \\
mbandaka & \\
\hline
\end{tabular}

Essas cepas de Lactobacillus foram utilizadas porque algumas pesquisas têm demonstrado que estas espécies são capazes de produzir bacteriocinas, inibindo as bactérias Gram-negativas, tais como: o patógeno Salmonella spp.

A parede celular da Salmonella é composta por uma camada de peptidioglicano e três outros componentes externos; lipoproteína, lipopolissacarídeo e membrana externa. A membrana exterior de bactérias Gram-negativas é o componente que confere maior resistência contra a ação de bacteriocinas.

\subsection{Preparação do Inoculo}

Os inóculos foram preparados reativando as cepas em meio de cultura específico e armazenados em microtubos contendo glicerol para preservação. Testes diretos (placas de Petri) e indiretos (espectrofotometria) foram realizados com cada cepa para verificar seu potencial de inibição contra as cepas de Salmonella ssp. utilizadas. 


\subsection{Padronização do Substrato}

O substrato foi preparado com melaço de soja diluído em água destilada até 5 e $10^{\circ}$ Brix e enriquecido com extrato de levedura, acetato de sódio, citrato de amônia, fosfato de amônia e tween 80. Após padronização do substrato, o mesmo foi esterilizado a $121^{\circ} \mathrm{C}$ por 15 minutos. Para o preparo do bioconservante em pó, o substrato utilizado foi adicionado de $10 \%$ de farelo de soja.

\subsection{Processo de Fermentação e obtenção do Bioconservante}

A fermentação foi realizada em incubador refrigerado (shaker), contendo o substrato padronizado e a cepa de Lactobacillus também padronizada conforme escala Mac Farland $\left(10^{6} \mathrm{UFC} / \mathrm{mL}\right)$. Para cada cepa foi realizada uma fermentação. As condições de fermentação foram de 24 horas com agitação a 110 rpm e temperatura específica de cada cepa. Amostras foram coletadas assepticamente a cada 8 horas de fermentação para monitoramento do $\mathrm{pH}$ e viabilidade das células.

Para purificação e concentração das bacteriocinas, as amostras foram centrifugadas, neutralizadas com $\mathrm{NaOH} 1 \mathrm{~N}$ para $\mathrm{pH} 7,0$, evaporadas a $40^{\mathrm{a}} \mathrm{C}$ em rotavapor e ultrafiltradas em membranas de 5000Da and 10000Da (1:10). Após concentração, as amostras foram esterilizadas em membrana 0.22 $\mu \mathrm{m}$ para remoção de qualquer microrganismo, restando apenas as bacteriocinas conforme demonstra a figura 1.

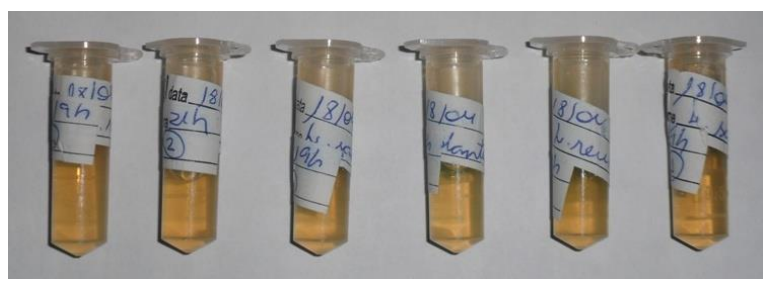

Figura 1 - Sobrenadantes neutralizados (sem células) fermentado por cepas de Lactobacillus

O material obtido resultante da fermentação do melaço de soja adicionado de farelo de soja foi neutralizado e seco a $40^{\circ} \mathrm{C}$ em estufa durante 72 horas, após secagem o mesmo foi moído, onde obteve-se o bioconservante em pó conforme mostra a figura 2.

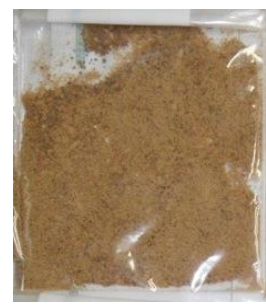

Figura 2 - Material fermentado por cepas de Lactobacillus, neutralizado e seco

Os produtos obtidos, foram testadas através do método de difusão em disco contra cepas de Salmonella spp. 
A natureza das bacteriocinas produzidas neste estudo foi determinada pela verificação da sua sensibilidade às enzimas tripsina, quimiotripsina e papaína pelo método de difusão em disco.

\subsection{Teste de Inibição da Salmonella spp. em Farelo de Soja}

O farelo de soja $46 \%$, 48\% e $62 \%$ de proteína foram esterilizados e contaminados com cada cepa de Salmonella spp. padronizada $\left(10^{8} \mathrm{UFC} / \mathrm{mL}\right)$. De acordo com o melhor resultado obtido nos testes de inibição com cada cepa de Lactobacillus e com cepas mistas, o substrato foi fermentado com um mix de cepas em um Bioreator de 15L sob as mesmas condições dos testes anteriores. O material obtido da fermentação, passou por neutralização e concentração. O bioconservante líquido e em pó foi adicionado em diferentes quantidades no Farelo de soja contaminado $(0,2 \%, 0,3 \%, 0,4 \%, 0,5 \%, 0,6 \%$, $0,7 \%$ e $0,8 \%$ ). Amostras foram coletadas para realizar a análise de Salmonella spp. para avaliação da inibição do patógeno.

\section{RESULTADOS E DISCUSSÃO}

\subsection{Avaliação das cepas de Lactobacillus}

Através do método direto em placas, observou-se que entre as sete cepas testadas, 57,15\% inibiram a Salmonella choleraesuis, e 28,60\% inibiram a Salmonella mbandaka. Barros et al. (2009) mostrou que $100 \%$ das amostras contendo Salmonella enteritidis apresentaram zonas de inibição de 16 a 24 mm de diâmetro usando cepas de L. salivarius e $86,7 \%$, utilizando cepas de L. reuteri com uma zona de inibição de 14-22 mm aplicando o método direto em placas.

Através do método indireto utilizando espectrofotômetro a 600nm, os melhores resultados de inibição de Salmonella spp. foram de 48-90\% de inibição para $S$. choleraesuis e 59-96\% de inibição para $S$. mbandaka. Todas as cepas avaliadas foram capazes de inibir o crescimento das cepas de Salmonella spp. utilizadas, sendo que houve uma inibição de $96 \%$ por L. plantarum e $92 \%$ por L. agilis.

Lash et al. (2005) mostraram que um sobrenadante livre de células fermentado por L. plantarum exibiu um efeito antibacteriano em uma ampla gama de espécies bacterianas por densidade óptica a $600 \mathrm{~nm}$. Em seu estudo, a inibição foi de mais de $90 \%$ para bactérias gram-negativas como a Escherichia coli, Pseudomonas aeruginosa, Serratia marcescens, Shigella flexneri e Salmonella typhimurium.

\subsection{Composição do Substrato}

Inicialmente, o melaço de soja a $5^{\circ}$ Brix tinha um total de $14,3 \mathrm{mg} / \mathrm{mL}$ de carboidratos, principalmente sacarose. Após 24 horas de fermentação ocorreu a diminuição para 2,3 mg/mL. Já o melaço de soja a $10^{\circ}$ Brix apresentou $27.1 \mathrm{mg} / \mathrm{mL}$ antes da fermentação e depois diminuiu para 1,9 $\mathrm{mg} / \mathrm{mL}$. Os resultados mostraram que ambas as concentrações de melaço de soja foram suficientes para a fermentação por Lactobacillus spp. 


\section{9 a 22 de outubro de 2014 \\ Florianópolis/SC}

\subsection{Fermentação do Substrato e Avaliação da Produção de Bacteriocinas}

$\mathrm{O}$ pH inicial do substrato era de 6,2 e após a fermentação do melaço de soja a $5^{\circ}$ Brix houve a redução para 4,0, já o melaço de soja $10^{\circ}$ Brix reduziu para 3,8. A produção de bacteriocinas ocorreu durante a fase exponencial para todas as cepas utilizadas e concentração do substrato (melaço de soja a 5 e $10^{\circ}$ Brix). Kelly, Asmudson e Huang (1996), cultivaram L. plantarum em caldo MRS a $28^{\circ} \mathrm{C}$ durante 24 horas, observaram a diminuição do $\mathrm{pH}$ de 6,0-3,8. Lewus e Monteville (2002) observaram que o aumento da produção de bacteriocina plantaricin $\mathrm{BN}$ ocorreu na fase exponencial de crescimento. $\mathrm{O}$ presente trabalho confirma os resultados obtidos por outros autores na produção de bacteriocinas.

As cepas de L. reuteri, L. salivarius, L. plantarum, L. agilis e L. plantarum (8014) foram empregadas individualmente e também combinadas para verificação da inibição da Salmonella spp. Os melhores resultados de inibição testados foram utilizando o sobrenadante fermentado de melaço de soja a $10^{\circ}$ Brix durante 8 horas, utilizando as cepas mistas (L. reuteri, L. agilis, L. plantarum e L. salivarius). Uma zona de inibição de 14 milímetros foi observada nas placas inoculadas para $S$. choleraesuis e 7 milímetros S. mbandaka. Lima et al. (2007) demonstraram por métodos diretos, incluindo o método de difusão em disco que, amostras de L. reuteri, L. salivarius e Lactobacillus sp. mostrou ação de bacteriocinas contra Enterococcus sp., Listeria monocytogenes e Salmonella spp. Barros et al. (2009) também confirmou que cepas de L. reuteri e L. salivarius isoladas de frangos, foram capazes de inibir a $S$. enteritidis, S. typhimurium, S. pullorum, S. agona, S. anatum, S. dublin e $S$. senftenberg in vitro. Isto confirma os resultados obtidos neste trabalho, onde foi possível inibir a Salmonella spp. utilizando uma mistura combinada de cepas de Lactobacillus spp. em melaço de soja $10^{\circ}$ Brix.

\subsection{Avaliação da Inibição da Salmonella spp. em Farelo de Soja}

A quantidade mínima necessária para a inibição de $S$. choleraesuis foi de 0,2\% e 0,4\% para $S$. mbandaka, utilizando os diferentes tipos de farelo de soja. A aplicação do biopreservante em pó afetou a cor do farelo de soja. Este é um parâmetro muito importante na sua comercialização, devido às exigências e necessidades dos clientes. A aplicação na forma líquida teve vantagens principais pois não afetou as características sensoriais do produto (cor, umidade e proteína) além de ser de fácil homogeneização.

\section{CONCLUSÃO}

Com base nos resultados obtidos neste estudo, podemos concluir que:

- Da combinação de cepas de Lactobacillus testadas, quatro mostraram um forte poder de inibição contra S. choleraesuis e S. mbandaka., sendo assim, as cepas selecionadas foram L. agilis, L. reuteri, L. salivarius e L. plantarum.

- A composição do substrato foi satisfatória para o processo de fermentação e produção de bacteriocinas na fase exponencial (após 8 horas). 
- A capacidade das cepas de Lactobacillus spp. produzirem bacteriocinas foi demonstrada, bem como a inibição da Salmonella spp. utilizando pequenas quantidades do Bioconservante líquido no Farelo de Soja.

- Uma patente do bioconservante desenvolvido foi depositada.

O produto desenvolvido utilizando melaço de soja como substrato tem grande potencial para ser aplicado em alimentos, equipamentos e/ou matérias-primas; Além disso, o substrato tem um custo baixo sendo economicamente viável quando comparado com o meio seletivo para Lactobacillus (MRS), pois é 160 vezes mais caro do que o melaço de soja.

\section{REFERÊNCIAS}

ANDRADE, M. A.; MESQUITA, A. J.; SOUZA, A. M.; BATISTA, M. A. C. Freqüência de Salmonella em granjas de postura comercial localizadas no município de Goiânia e entorno. Anais da Escola de Agronomia e Veterinária da Universidade Federal de Goiás, v.25, n.2, p.21-26, 1995.

BARROS, M.R.; ANDREATTI FILHO, R.L.; LIMA, E.T. and CROCCI, J.A. Avaliação in vitro da atividade inibitória de Lactobacillus spp., isolados do inglúvio e cecos de aves sobre Salmonella. Arquivo Brasileiro de Medicina Veterinária e Zootecnia, v.61, n.4, p.863-868, 2009.

D'AOUST, J. Foodborne salmonellosis: current international concerns. Food Safety Magazine; n.7, p.10-17, 2001.

DE MARTINIS, E. C. P.; ALVES, V. F.; FRANCO, B. D. G. M. Fundamentals and perspectives for the use of bacteriocins produced by lactic acid bacteria in meat products. Food Reviews International, v.18, n.2-3, p.191-208, 2002.

EUROPEAN FOOD SAFETY AUTHORITY - Opinion of the Scientific Panel on Biological Hazards on the request from the Commission related to "Risk assessment and mitigation options of Salmonella in pig production”, The EFSA Journal n.341, p.1-131, 2006.

JACK, R. W.; TAGG, J. R.; RAY, B. Bacteriocins of gram positive bacteria. Microbiology Review, v.39, n. 2, p.171-200, 1995.

KELLY, W.J.; ASMUDSON, R.V.; HUANG, C.M. Characterization of plantaricin KW30, a bacteriocin produced by Lactobacillus plantarum. Journal of Applied Bacteriology, v.81, p.657-662, 1996.

LASH B.W., MYSLIWIEC T.H., GOURAM H., Detection and partial characterization of a broadrange bacteriocin produced by Lactobacillus plantarum (ATCC 8014). Food Microbiology, n.22, p.199-204, 2005.

LEWUS, C.B.; MONTVILLE, T.J. Detection of bacteriocins produced by lactic acid bacteria. Journal of Microbiology Methods, v.13, p.145-150, 1991.

LIMA, E. T., R. L. ANDREATTI FILHO, A. S. OKAMITO, J. C. NOUJAIM, M. R. BARROS and A. J. CROCCI. Evaluation in vitro of the antagonistic substances produced by Lactobacillus spp. isolated from chickens. Canadian Journal of Veterinary Research, p.71:103-107, 2007. 
MORITA M., KOBAYASHI A., YAMASHITA T., SHIMANUKI T., NAKAJIMA O. and TAKAHASHI S., Functional analysis of basic transcription element binding protein by gene targeting technology, Molecular and Cellular Biology, n.23, p.2489-2500, 2003.

NASCIMENTO, M. S.; BERCIERT JR, A.; BARBOSA, M. D.; ZANCAN, F. T.; ALMEIDA, W. A. F. Comparações de meios de enriquecimento e de plaqueamento utilizados na pesquisa de Salmonella em carcaças de frango e fezes de aves. Revista Brasileira de Ciência Avícola, v.2, n.1, p.85-91, 2000.

NASCIMENTO, M. S.; MORENO, L.; KUAYE, A, YOSHITERU. Bacteriocinas em alimentos: uma revisão. Brazilian Journal of Food Technology, v.11, n.2, p.120-127, 2008.

PELCZAR, M.; REID, R.; CHAN, E. C. S. Infecções humanas transmitidas pelos alimentos e pela água, Microbiologia, v.2, p.689-722, 1981.

ROSA, C. M., FRANCO, B. MORENO. Bacteriocinas de bactérias láticas. Consciência e Saúde, Revista Científica UNINOVE, v.1, p.09-15, 2002.

TESSARI, E. N. C.; CARDOSO, A. L. S. P.; CASTRO, A. G. M.; ZANATTA, G. F.; KANASHIRO, A. M. I. Incidência de Salmonella spp em pintos de corte recém nascidos. Arquivo do Instituto Biológico, v.70, n.3, p. 278-281, 2003.

TODOROV, S.D. Bacteriocins from Lactobacillus plantarum production, genetic organization and mode of action. Brazilian Journal Microbiology, n.40, p.209-221, 2009. 